\title{
Percutaneous fixation in the treatment of traumatic thoracolumbar fractures: a current view of this minimally invasive surgery
}

\begin{abstract}
Thoracolumbar fractures are common and can cause serious injury and profound changes in patients' quality of life. Currently there are several treatment options available for thoracolumbar fractures ranging from conservative treatment (in stable fractures) to the various surgical techniques, in unstable fractures. The treatment of unstable traumatic thoracic and lumbar spine fractures remains controversial, not existing in the current literature, enough evidence about the best treatment among the various surgical options available. The Orthopedists must be therefore attentive to this entity, given the increasing trend of such fractures.

This study focused on a minimally invasive surgical procedure currently featured in the treatment of thoracolumbar fractures, percutaneous fixation. This work focused on the literature review of percutaneous fixation applied in the treatment of traumatic thoracolumbar fractures, in order to acquire the latest knowledge in the various dimensions of this technique, particularly, the indications for its implementation, advantages and limitations of its use and evaluation of its efficacy and safety. A search was performed in Pubmed/Medline with the words "thoracolumbar fracture", "percutaneous fixation", "minimally invasive spine surgery", "posterior approach", "spine surgery", especially selecting articles published in the last 15 years, including original and review articles, in Portuguese and English languages. Percutaneous fixation constitutes a technically more demanding procedure as a higher learning curve, as well as the need for specific instrumentation and more expensive material, it should be current and necessary to meet the impact or importance of this minimally invasive approach, in the treatment of thoracolumbar fractures.
\end{abstract}

Keywords: thoracolumbar fracture, percutaneous fixation, minimally invasive surgery, posterior approach, spine surgery
Volume 3 Issue I - 2018

\author{
Ana Costa Pinheiro,' Margarida Areias,' \\ Carolina Oliveira,' Cristina Varino Sousa, ${ }^{2}$ \\ Luís Pires Silva, ${ }^{2}$ Miguel Leal ${ }^{3}$ \\ 'Internos Ortopedia ULSAM,Viana do Castelo, Portugal \\ ${ }^{2}$ Assistentes Ortopedia ULSAM, Viana do Castelo, Portuga \\ ${ }^{3}$ Diretor de Serviço Ortopedia ULSAM,Viana do Castelo, \\ Portugal
}

Correspondence: Ana Costa Pinheiro, Unidade Local de Saúde do Alto Minho,Viana Castelo, Portugal, Tel 914335860, Email ana.alexandra.pinheiro@gmail.com

Received: August 16, 2017| Published: February 02, 2018

\section{Introduction}

Thoracolumbar fractures are frequent and can lead to serious injuries and profound changes in patients' quality of life. ${ }^{1}$ There are currently several treatment options available for thoracolumbar fractures, ranging from conservative treatment (in stable fractures) to various surgical techniques in unstable fractures. ${ }^{2}$ The treatment of unstable traumatic fractures of the thoracic and lumbar spine remains controversial, and there is insufficient evidence in the current literature about the most appropriate treatment among the various surgical options available. ${ }^{3}$ Orthopedists should therefore be attentive to this entity, given the increasing trend of this type of fracture.

The present study focused on a minimally invasive surgical modality, currently highlighted in the treatment of thoracolumbar fractures, percutaneous fixation (PF). Literature demonstrates that in this minimally invasive surgery, complications among patients are rare, reporting a few cases of non-healing of the fracture site, wound infection and a misplaced screw. In a study, Chaichana et al. ${ }^{1}$ reported that the average surgery time was only 91 minutes, with an average blood loss of 95 milliliters. No patients experienced increased weakness, and the majority had improved pain and kyphosis correction at last follow-up. They showed that this type of surgery can be performed relatively quickly, with minimal blood loss, and with minimal surgical morbidity. This technique is valuable to expeditiously immobilize a thoracolumbar fracture with minimal or no kyphosis and no neurological deficits. Older patients and patients who sustained polytrauma are the patients who may benefit the most from minimally invasive surgery.

The objective of this study was to review the literature about PF in the treatment of traumatic thoracolumbar fractures to acquire the latest knowledge in the various dimensions of this technique, namely with regard to indications for its accomplishment, advantages and limitations of its use and evaluation of their effectiveness and safety. Percutaneous fixation constitutes a technically more demanding procedure as a higher learning curve, as well as the need for specific instrumentation and more expensive material, it should be current and necessary to meet the impact or importance of this minimally invasive approach, in the treatment of thoracolumbar fractures.

\section{Definition, epidemiology, classification and treatment of thoracolombar fractures}

Most spinal fractures occur in the thoracolumbar region, in the transition between the immobile thoracic segment and the more mobile lumbar segment. These fractures often occur because of high energy trauma (road accidents and falls in height), between 20-40 years, and as a result of low energy trauma (falls of the same height) in geriatric patients. ${ }^{1,2}$ It is known that $90 \%$ of vertebral fractures occur 
in the thoracolumbar spine and about $60 \%$ of these fractures occur between T11-L2. ${ }^{1}$ Neurological lesions complicate about $15-20 \%$ of this type of fracture. ${ }^{1}$

Several classifications of thoracolumbar fractures are described, with Denis (1984) and Magerl (1994) being the most commonly used classification. The classification of Magerl, adopted by AO-ASIF, is composed of 3 large groups/types (A, B and C), which in turn branch into 9 subtypes, each type referring to the mechanism of trauma/force applied and correlates with the degree of fracture instability/severity (more severe and unstable in type C3 fractures and less severe and more stable in type A1 fractures). ${ }^{1}$ There are currently several treatment options available for thoracolumbar fractures, ranging from conservative treatment (in stable fractures) to various surgical techniques in unstable fractures. ${ }^{3}$ The factors most valued in the treatment decision include neurological status, spine stability, degree of deformity and presence of associated lesions.

The deterioration of the neurological state in the presence of persistent neural compression and the lesion with complete rupture of the ligament complex associated with dislocation, appearing gross instability, are the absolute indications for the surgical treatment of thoracolumbar fractures. ${ }^{3}$ It should be noted that the "TLICS" score (Thoracolumbar Injury Classification and Severity Score) is an objective and simple way of evaluating the most important factors in the choice of treatment, namely the morphology of the lesion, the integrity of the posterior ligament complex and the neurological state of the patient. ${ }^{1-3}$

The surgical treatment of thoracolumbar fractures is aimed at reducing the vertebral deformity caused by trauma, restoring the anatomy of the vertebral canal (in the presence of spinal compression) and consolidating the fracture through stabilization and adequate osteosynthesis. ${ }^{4}$ There is still no consensus regarding the most appropriate treatment of the various traumatic thoracolumbar fractures. ${ }^{5,6}$ Within the surgical techniques, the PF have come to stand out as an alternative to the traditional open approaches in the treatment of this type of fractures. ${ }^{5,6}$

\section{Epidemiology of the toracolombar PF}

PF was first described in 1977 by Magerl and later by Dick. ${ }^{7,8}$ Minimally invasive PF surgery has been applied in the treatment of spinal fractures increasingly in the last 10 years. Although primarily aimed at degenerative spine surgery, it was later used in the traumatic, infectious and neoplastic pathology.,9 Traditional surgical techniques may be associated with significant morbidity, and in recent years PF has been presented as a promising alternative. ${ }^{10,11}$

\section{Indications}

There is no consensus about the indications for PF in the treatment of thoracolumbar fractures. However, it is considered that isolated $\mathrm{PF}$, not associated with other techniques, can only be used in type A fractures (compression trauma, A1-impacted, A2-separation and A3-explosion) and type B2 (distraction trauma, with posterior bone injury). In such cases, the fixation provides rapid relief of pain corrects deformity and prevents further damage. However, PF may be associated with other techniques in the treatment of more complex fractures. ${ }^{7}$ According to Heintel et al. PF should be preferentially used in the slightly deviated fractures, and its performance in fractures with significant deviation is controversial. ${ }^{12}$

\section{Clinical and radiological results}

Wang considered $\mathrm{PF}$ as a good therapeutic option in type A thoracolumbar fractures, with significant differences between this technique and traditional open surgery, regarding incision size (Figure 1) blood loss, surgical time, hospitalization period, need for blood transfusion and postoperative analgesia. However, there were no differences between these two techniques regarding the radiological results obtained (Figure 2-6). ${ }^{13}$

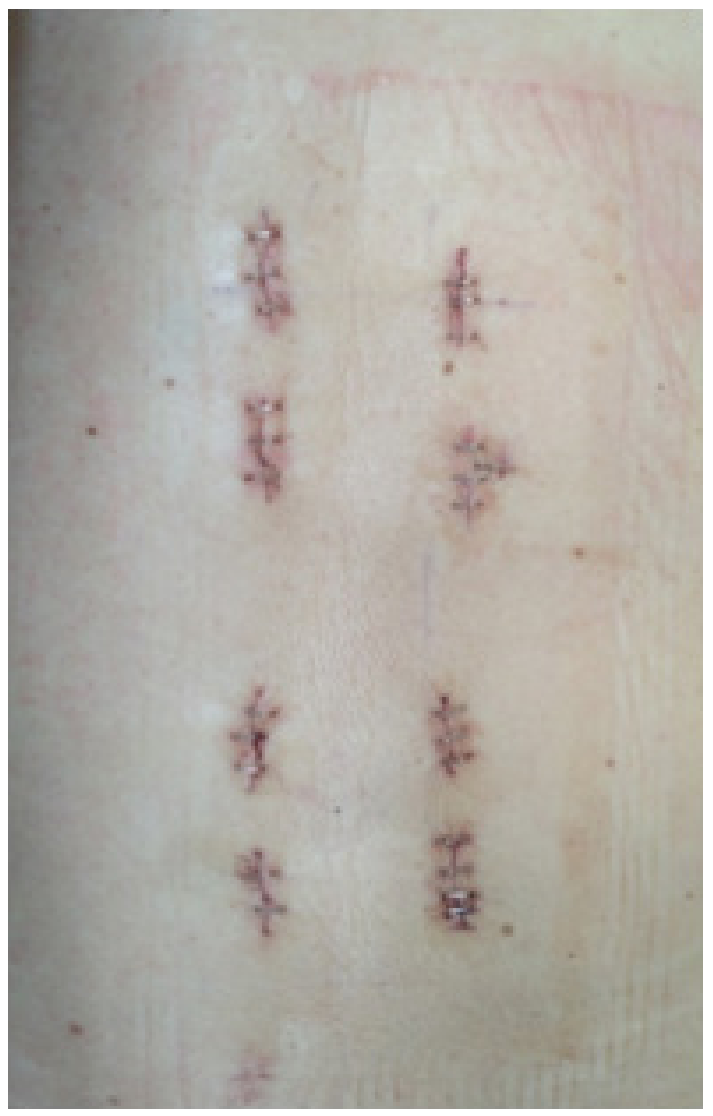

Figure I Postoperative incisions image after percutaneous fixation.

Grossbach et al. ${ }^{10}$ studied 39 patients with thoracolumbar fractures associated with posterior ligament complex injury. These authors observed radiographic improvements in both types of surgery, although they did not find significant differences in ASIA Score or degree of kyphosis. ${ }^{10}$ However, they found less surgical time and less hemorrhage in PF. ${ }^{10,14,15}$ However, Wild did not verify differences between the two surgical techniques in terms of surgical time, time of radiation exposure and loss of fracture reduction. ${ }^{15}$

Zhonghua et al. did not find significant differences between these two types of surgery regarding the duration of surgery, the level of preoperative pain and the degree of pre and postoperative kyphosis angiography. However, they found significant differences in intraoperative blood loss and pain level in the first postoperative week. ${ }^{16,17}$ In this study, no iatrogenic neurological damage was recorded. ${ }^{16} \mathrm{PF}$ has a clinical efficacy similar to that found in traditional surgery, with the advantage of being less invasive and allowing a faster recovery and associated with a low incidence of chronic low back pain. ${ }^{16,17}$ 


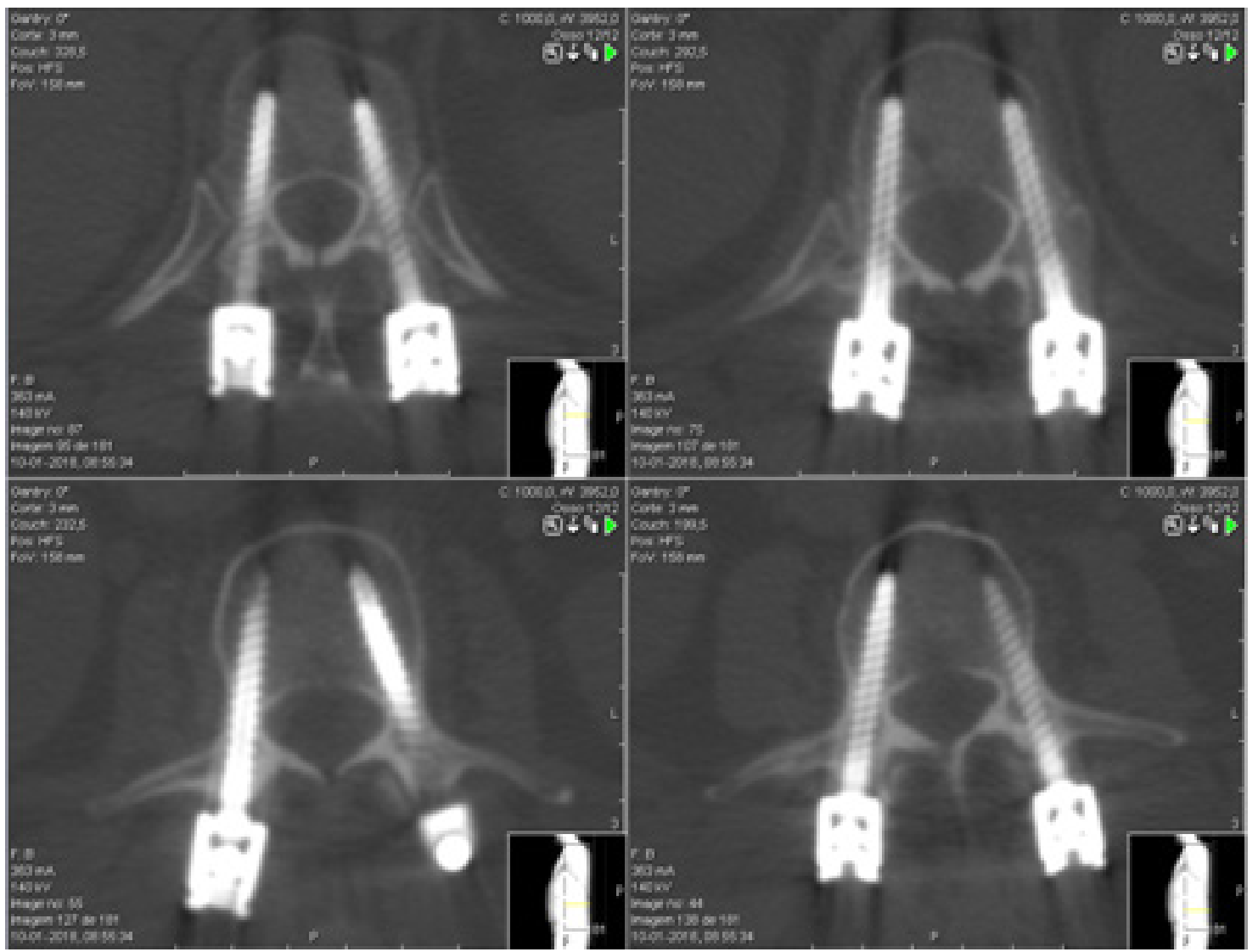

Figures 2-5 Postoperative computerized axial tomography images after percutaneous fixation.
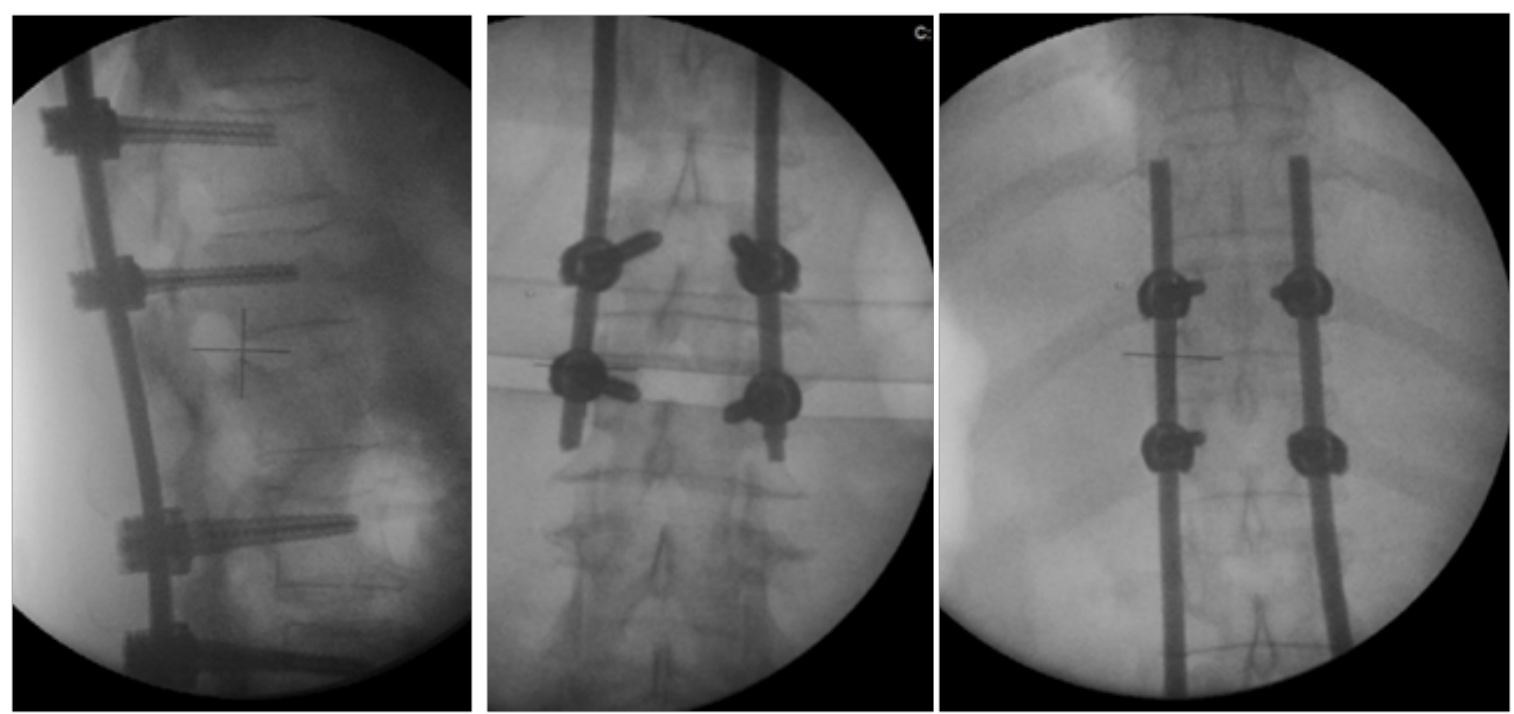

Figures 6 Postoperative X-ray images after percutaneous fixation.

Charles et al. ${ }^{18}$ suggested that PF associated with anterior fusion provided good clinical results. Schmidt et al obtained a low complication rate, with reduced surgical time and minimal blood loss, benefiting polytrauma patients and elderly patients with high perioperative risk. ${ }^{19}$

Fourney et al. ${ }^{20}$ found no differences in the rate of complications between traditional surgery and minimally invasive surgery. Teyssédou et al. ${ }^{6}$ obtained a low rate of complications and radiological results similar to those obtained in other studies.

$\mathrm{PF}$ is a relatively safe and effective technique for the treatment of specific types of thoracolumbar fractures, obtaining satisfactory clinical and radiological results with reduced damage to the soft tissues.,13,21-31 This technique may be applied in various vertebral pathologies, with or without the use of additional surgical 
procedures, such as intervertebral fusion or spinal decompression if necessary. ${ }^{23,24,32}$ The technique under study demonstrates to be an attractive therapeutic option, obtaining encouraging results although its indications and limitations need to be carefully delineated. Pelegri et al. ${ }^{34}$ have seen in PF an intermediate method between conservative treatment and traditional open surgery. 33,34

\section{Advantages}

Some of the advantages pointed out to PF in the treatment of thoracolumbar fractures are the fact of sparing the paravertebral muscles, thus avoiding muscular atrophy due to denervation and devascularization of the muscle. The studies appear to show a decrease in the amount of blood lost intraoperatively, a reduced need for blood transfusion and a decreased risk of infection. , $10,13,35-37^{\text {There }}$ has been a decrease in postoperative pain and reduced loss of muscle strength, as well as a reduction in the hospitalization period, making rehabilitation easier and faster. ${ }^{17,38,39}$ Although there is no unanimity, the fixation material used in percutaneous osteosynthesis is usually removed 8-12 months after stabilization of the fracture through the scar at the insertion site of the screws, thus allowing the removal of the material in the absence of extensive approaches. ${ }^{9,40}$

\section{Limitations}

PF presents some limitations, namely exposure to radiation during the precise placement of the screws, exposing the surgeon and other surgical team and the patient himself at cumulative doses of radiation. ${ }^{7,40}$ This is an important problem for the surgeon throughout his career, which should be minimized through the methods currently available. ${ }^{7}$ Another limitation to this technique is the fact that it is contraindicated in fractures associated with neurological deficits, given the impossibility of spinal decompression. This limitation can be overcome by the combined use of PF with other techniques.?

\section{Conclusion}

Thoracolumbar fractures are among the most common type of traumatic spine fractures. Management of unstable fractures is varied, typically involves open surgery with short-segment pedicle screw fixation. Nevertheless, not all patients can tolerate this procedure since the prolonged operating time, large volume blood loss, paraspinal muscle injury and denervation, among others causes. The use of minimally invasive, percutaneous pedicle screw fixation has been growing with developments in surgical techniques and instrumentation. However, its use for traumatic thoracolumbar fractures has been limited to case reports and small case series. Despite the shortage of long-term studies, in recent years, minimally invasive surgery by PF, has achieved popularity in the treatment of thoracolumbar fractures, due to the good clinical and radiological results obtained in the short and medium term. As reported by other studies, it is permissible to classify this technique as safe, with low rates of surgical complications, mortality, and reduced hospitalization periods.

The incidence of complications obtained by this technique, based on data reported in the literature, appears to be low. Multifidus muscle dysfunction, associated with more aggressive surgical techniques, has been implicated in the pathophysiology of chronic low back pain after surgery. The PF, because it is a minimally invasive surgery, reduces the probability of occurrence of this entity responsible for large expenditures in Health. PF can be considered effective in that it obtains clinical and radiographic results like those obtained by traditional open surgery, but with less soft tissue damage.

In general, the surgical treatment of traumatic thoracolumbar fractures, through PF, is safe and effective, being an added value in the treatment of these fractures in polytraumatized patients and in the elderly.

The literature demonstrates that minimally invasive surgery can be successfully achieved with minimal morbidity in neurologically intact patients with traumatic thoracolumbar fractures. As mentioned, older patients and patients with polytrauma may most benefit from this approach. The results presented by the various papers analyzed and described in the literature highlight the efficacy and safety of PF in the treatment of thoracolumbar fractures. Although the short-term results suggest efficacy and safety similar to those of conventional open surgery (although presenting some advantages in relation to this), it would be pertinent, in future investigations, to recommend further studies in the long term.

Similarly, the degree of satisfaction of the patients submitted to this technique should be evaluated using questionnaires, given the improvement in patients' quality of life, and it is also very important to classify the efficacy of this surgical technique. Further comparative studies between minimally invasive PF and other surgical techniques in the treatment of traumatic thoracolumbar fractures would be relevant in order to define the position of the technique under study in the field of this type of fracture. PF seems, however, an alternative method to conventional surgeries, in the treatment of specific types of thoracolumbar fractures. The technique under study is an attractive therapeutic option and offers encouraging results, although its indications and limitations need to be carefully studied.

\section{Acknowledgements}

None.

\section{Conflict of interest}

The author declares that there is no conflict of interest' for publication of manuscript.

\section{References}

1. Rockwood, Green's. Fractures in Adults. 7th ed. In: Buchholz R, Court BC, editors. Philadelphia, USA: Lippincott Williams \& Wilkins; 2010.

2. Chaichana KL, Garza RRD, Sciubba DM, et al. Minimally invasive percutaneous pedicle screw fixation for thoracolumbar spine fractures: Case report and review of literature. J Trauma Treat. 2012;1:134.

3. Cappuccio M, Amendola L, Paderni S, et al. Complications in minimally invasive percutaneous fixation of thoracic and lumbar spine fractures. Orthopedics. 2013;36(6):729-734.

4. Alain J. Anterior spine surgery in recent thoracolumbar fractures: An update. Orthopaedics \& traumatology: Surgery \& Research. 2011;97(5):541-554.

5. Oppenheimer JH, DeCatro I, McDonnell DE. Minimally invasive spine technology and minimally invasive spine surgery: a historical review. Neurosurgery Focus. 2009;27(3):9-14.

6. Teyssédou S, Saget M, Prébet R, et al. Evaluation of percutaneous surgery in the treatment of thoracolumbar fractures. Preliminary results of a prospective study on 65 patients (article in german). Orthopaedics \& traumatology: Surgery \& Research. 2012;98(1):39-47. 
7. Court C, Vincent C. Percutaneous fixation of thoracolumbar fractures current concepts. Orthopaedics \& traumatology: Surgery \& Research. 2012;98(8):900-909.

8. Huang W, Luo T. Efficacy analysis of pedicle screw internal fixation of fractured vertebrae in the treatment of thoracolumbar fractures. Experimental and Therapeutic Medicine. 2013;5(3):678-682.

9. banagan $\mathrm{k}$, ludwig $\mathrm{s}$. thoracolumbar spine trauma: when damage control minimally invasive spine surgery is an option. seminars in spine surgery. 2012;24(4):221-225.

10. Grossbach AJ, Dahdaleh NS, Abel TJ, et al. Flexion-distraction injuries of the thoracolumbar spine: open fusion versus percutaneous pedicle screw fixation. Neurosurgery Focus. 2013;35(2):2-8

11. Mobbs R, Sivabalan P, Li J. Technique, challenges and indications for percutaneous pedicle screw fixation. J Clin Neurosci. 2011;18(6):741749

12. Heintel TM, Berglehner A, Meffert R. Accuracy of percutaneous pedicle screws for thoracic and lumbar spine fractures: a prospective trial. Eur Spine J. 2013;22(3):495-502.

13. Wang HW, Li CQ, Zhou Y, et al. Percutaneous pedicle screw fixation through the pedicle of fractured vertebra in the treatment of type A thoracolumbar fractures using sextant system: an analysis of 38 cases Chinese Journal Traumatology. 2010;13(3):137-145.

14. Grass R, Biewener A, Dickopf A, et al. Percutaneous dorsal versus open instrumentation for fractures of the thoracolumbar border. A comparative, prospective study. Unfallchirurgie. 2006;109(4):297-305.

15. Wild M, Glees M, Plieschnegger C, et al. Five-year follow-up examination after purely minimally invasive posterior stabilization of thoracolumbar fractures: a comparison of minimally invasive percutaneously and conventionally open treated patients. Arch Orthop Trauma Surgery. 2007;127(5):335-343.

16. Luo $\mathrm{P}, \mathrm{Xu} \mathrm{LF}, \mathrm{Ni} \mathrm{WF}$, et al. Therapeutic effects and complications of percutaneous pedicle screw fixation for thoracolumbar fractures. Zhonghua Wai Ke Za Zhi. 2011;49(2):130-134

17. Chen Z, Zhao JQ, Fu JW, et al. Modified minimally invasive percutaneous pedicle screws osteosynthesis for the treatment of thoracolumbar fracture without neural impairment. Zhonghua Yi Xue Za Zhi. 2010;90(21):14911493.

18. Charles YP, Walter A, Schuller, et al. Thoracolumbar fracture reduction by percutaneou in situ contouring. European Spine Journal. 2012;21(11):2214-2221.

19. Schmidt OI, Strasser S, Kaufmann V, et al. Role of the early minimalinvasive spine fixation in acute thoracic and lumbar spine trauma. Indian Journal Orthopaedics. 2007;41(4):374-380.

20. Fourney DR, Dettori JR, Norvell DC, et al. Does minimal access tubula assisted spine surgery increase or decrease complications in spinal decompression or fusion? Spine. 2010;35(9):57-65.

21. Blondel B, Fuentes S, Pech GG, et al. Percutaneous management of thoracolumbar burst fractures: Evolution of techniques and strategy. Orthopaedics \& traumatology: Surgery \& Research. 2011;97(5):527532

22. Fang LM, Zhang YJ, Zhang J, et al. Minimally invasive percutaneous pedicle screw fixation for the treatment of thoracolumbar fractures and posterior ligamentous complex injuries. Beijing Da Xue Bao. 2012;44(6):851-854

23. Yang WE, Ng ZX, Koh KM, et al. Percutaneous pedicle screw fixation for thoracolumbar burst fracture: a Singapore experience. Singapore Medicine Journal. 2012;53(9):577-581.

24. De Lure F, Cappuccio M, Paderni S, et al. Minimal invasive percutaneous fixation of thoracic and lumbar spine fractures. Minimal Invasive Surgery. 2012;1410-1432.
25. Marin A, Herrero C, Barbosa M, et al. Percutaneous fixation in the treatment of thoracolumbar fractures: preliminary results. Columna. $2013 ; 12(2)$.

26. Barbagallo GM, Yoder E, Dettori JR, et al. Percutaneous minimally invasive versus open spine surgery in the treatment of fractures of the thoracolumbar junction: a comparative effectiveness review. Evid Based Spine Care Journal. 2012;3(3):43-49.

27. Bironneau A, Bouquet C, Millet BB, et al. Percutaneous internal fixation combined with kyphoplasty for neurologically intact thoracolumbar fractures: a prospective cohort study of 24 patients with one year of follow-up. Orthopaedics traumatology: Surgery \& Research. 2011;97(4):389-395.

28. Lendemans S, Hussmann B, Kauther MD, et al. Minimally invasive dorsal stabilization of the thoracolumbar spine. Unfallchirurgie. 2011;114(2):149-159.

29. Venmans A, Lohle PN, Van Rooij WJ, et al. Frequency and outcome of pulmonary polymethylmethacrylate embolism during percutaneous vertebroplasty. American Journal of Neuroradiology. 2008;10:19831985.

30. Verlaan JJ1, Diekerhof CH, Buskens E, et al. Surgical treatment of traumatic fractures of the thoracic and lombar spine. A systematic review of the literature on techniques, complications and outcome. Spine. 2004;29(7):803-814.

31. Von Jako R, Michael AF, Kenneth SY, et al. Minimally invasive percutaneous transpedicular screw fixation:increased accuracy and reduced radiation exposure by means of a novel electromagnetic navigation system. Acta Neurochirurgie. 2011;153(3):589-596.

32. Ozkan N, Ibrahim ES, Ondra P, et al. Minimally invasive transpedicular dorsal stabilization of the thoracolumbar and lumbar spine using the minimal access non-traumatic insertion system (MANTIS): preliminary clinical results in 52 patients. Journal Neurological Surgery and Cent European Neurosurgery. 2012;73(6):369-376.

33. Palmisani M, Gasbarrini A, Barbanti BG, et al. Minimally invasive percutaneous fixation in the treatment of thoracic and lumbar spine fractures. European Spine Journal. 2009;18(1):71-74.

34. Pelegri C, Winter M, Brassart N, et al. Percutaneous osteosynthesis of lumbar and thoracolumbar spine fractures without neurological deficit surgical technique and preliminary results (article in french). Review Chirurgie Orthopaedics Reparatrice Appar Motor. 2008;94(5):456-463.

35. Grass R, Biewener A, Dickopf A, et al. Percutaneous dorsal versus open instrumentation for fractures of the thoracolumbar border. A comparative, prospective study. Unfallchirurgie. 2006;109(4):297-305.

36. Jiang XZ, Tian W, Liu B. Comparison of a paraspinal approach with a percutaneous approach in the treatment of thora columbar burst fractures with posterior ligamentous complex injury: a prospective randomized controlled trial. Journal International Medicine and Research. 2012;40(4):1343-1356

37. Luo $\mathrm{P}, \mathrm{Xu} \mathrm{LF}, \mathrm{Ni} \mathrm{WF}$, et al. Therapeutic effects and complications of percutaneous pedicle screw fixation for thoracolumbar fractures. Zhonghua Wai Ke Za Zhi. 2011;49(2):130-134.

38. Tannous O, Shiu B, Koh E. Minimally invasive surgery for thoracolumbar spine fractures: spine stabilization damage control. Seminars in Spine Surgery. 2013;25(3):170-175.

39. Karp J, Ludwig S. The role of minimally invasive surgery for thoracolumbar spine trauma. Seminars in Spine Surgery. 2011;23(1):60 65

40. Bronsard N, Bolia $\mathrm{T}$, Challalia $\mathrm{M}$, et al. Comparaison empre l'ostéosynthèse percutanée et des classique fraturas thoracolombaires: irradiação et résultats. Revue de Chirurgie orthopédique et Traumatologique. 2013;99(2):130-137. 